\title{
Properties of High-Strength Concrete Filled Steel Tube Columns
}

\author{
Kefeng $\operatorname{Tan}^{1}$, John M. Nichols ${ }^{2}$ \\ ${ }^{1}$ Department of the Materials Science School at the South West University of Science and Technology, Mianyang \\ City, Sichuan Province, PRC \\ ${ }^{2}$ Department of Construction Science, College of Architecture, Texas A\&M University, College Station, TX, \\ 77840, USA \\ Email: jm-nichols@tamu.edu
}

\begin{abstract}
High Strength Concrete Filled Steel tubes (CFST) provide a common construction material in China. The purpose of this research was to determine the axial load properties for CFST subjected to concentric and eccentric loading in a series of experiments. The results show that the magnitude of experimentally measured compressive strength increases for the core concrete, due to the confinement from the steel that is proportional to the ratio of the area of steel to the area of concrete. If the slenderness ratio is kept constant the columns bearing capacity and maximum strain decreases as the eccentricity to radius ratio increases. Formulas to estimate the load bearing capacity for short and for slender eccentrically loaded columns were established from the data. The results have been compared statistically to other published results to show that a general linear form of the capacity equation is warranted for High Strength Concrete Filled Steel tubes.
\end{abstract}

Keywords: Concrete filled steel tubes, high strength concrete, bridge construction.

\section{Introduction}

The purpose of this research is to experimentally investigate the properties of concrete filled steel tubes (CFST) using a high strength concrete core. The experimental work investigates the ductility and strength properties of steel tubular columns filled with a high strength concrete core, using short and slender columns subjected to either concentric or eccentric loads. The results are compared to recent published data from the USA, Australia, and China [1-12]. The protocol for the column compression tests used both concentric and eccentric load rigs. The columns used in the experiments have length to diameter ratios ranging from 3.5 to 15 . This paper outlines the literature relevant to this work, provides a methods section, outlines and summarizes the results and the key findings, and provides a conclusion.

\section{Literature Review}

CFST column types have been used in recent high-rise structures in China [13-22]. CFST structures are emerging as an important structural system for new buildings, particularly for providing earthquake resistance. Steel tubular columns filled with normal strength concrete (NSC) have been studied using slender and eccentrically loaded units [23, 24], and based on these studies; a design code has been established for Chinese use [25].

A sketch of a typical CFST building connection showing a column and beam connection is drawn in Figure 1. This sketch provides the definitions of the steel wall thickness, diameter of the steel tube and the area of the concrete core of the composite tube. The schematic format of the connection detail shown in Figure 1 comes from a recent Chinese building. The connection detail has been simplified by reducing the number of bolt holes and stiffener plates. The steel plate for the beam connection transfers the load to the steel tube, which relies on the concrete to provide buckling restraint and increased strength for the given cross-sectional area.

An early comment on the original work suggested that a direct comparison should be shown in the paper with other published results on CFST. Additional data have been used from O'Shea and Bridges [26] and Sakino et al. [21] to broaden the statistical analysis results for CFST systems. 
Other recent compression tests research for CFST column loading has investigated the difference between applying the loading directly to the concrete core or directly onto a steel end plate. Concrete filled steel tube is not a homogenous material; it is a composite with two distinct geometric material zones, the inner concrete core, and the outer steel cylinder each with different elastic and plastic properties. There is also the problem of determining the bond strength between the steel and the concrete core, and the properties of the interface once the bond is broken. Comparison of these experimental results with previous research findings will consider the potential differences due to these alternative finish conditions on the top surface of the specimens.

The current test samples bases are steel plates to facilitate manufacture. The various researchers did not consider or analyse the experimental impact from using different end loading methods [23, 24, 26-32]. This is an interesting omission from the previous work, which has been considered in this paper. A simple statistical analysis, presented in this paper, shows a difference in the experimental results for the various end loading conditions. The analytical work in this paper allows for the statistical differences in the previously reported experimental results for the varying end restraint types and compares the results with this current experimental work.

A recent study on concentrically loaded CFST short columns, with slenderness ratio of 3.5, has confirmed that under the confinement of steel tube, the strength of the core concrete was improved significantly. This results from the bi-axial compression applied by the steel confinement because of the approximately ten to one differential ratio of the Young's modulus of the steel (200 GPa) and concrete (20 to $40 \mathrm{GPa}$ ). The use of the steel confinement changes the failure of the general brittle plain concrete columns to a general ductile failure mode [33]. Other research has shown that when the slenderness ratio is less than four, the CFST columns can be fully and concentrically loaded without stability problems [32]. The slenderness ratio for CFST columns has usually been greater than four for real buildings, so determining the properties of these slender columns using high strength concrete presents a currently required research challenge. The confinement index was defined using the ultimate compressive concrete compressive strength, $f_{c u}^{\prime}$, the concrete cylinder compressive stress, $f_{c}^{\prime}$, the concrete area, $A_{c}$, the steel strength, $f_{s t}^{\prime}$, and the steel area, $A_{s}$, as:

$$
\Phi=A_{s} f_{s t}^{\prime} / A_{c} f_{c}
$$

One area of research identified for these types of columns was in the use of higher strength core concrete to $100 \mathrm{MPa}$. Xiong et al. [34] provide an excellent summary of the current knowledge about the performance of concrete filled steel tubes, subjected to flexural loads. Chen et al.[35] outline a research into bond slip behaviour of concrete filled steel circular hollow section tubes. Alostaz and Schneider [36] analyze with finite elements the behaviour of eight typical connection details for CFST column to steel beam connections. Their results show the need for stiffness at the connection to avoid large distortion in the steel plate and to allow for transfer of load into the concrete core.

Mursi and Uy [37] outline the status of the design standards for CFST structures if the plate is stocky; noting the design guidance in the typical codes is adequate. The use of steel tubes provides an effective and permanent formwork speeding the overall construction process. Fire resistance of the composite material has been investigated and shown to be adequate with coating materials [38].

The difficulty in comparing the results from the Australian, American, and Chinese sources is due to the differences in a defined characteristic strength for concrete, which requires the use of the scale factors to account for different testing sizes and shapes of the plain concrete specimens used by the different experimenters [25, 39, 40].

The simplest linear mathematical representation of the load capacity of a CFST system is presented in equation (2):

$$
N_{c}=\xi A_{c} f_{c}^{\prime}+\zeta A_{s} f_{s t}^{\prime}
$$

Here $N_{c}$ is the capacity of the combined column, $\xi$ and $\zeta$ are variables in the equation that can be determined from the experimental data. This is the most general linear form of the capacity equation for the CFST tube. The investigation of a non-linear equation would require significantly more experimental work.

There has been a significant increase and change in the manufacture of concrete in the last three decades. This study used moderately high strength concrete, although recent developments in flowable concretes provide an alternative that should improve the placement of concrete in CFST buildings. One 
of the uses for CSFT is arch bridges. A typical use is in a long span CFST bridge such as the Beipanjiang Railroad Bridge [41]. This bridge was constructed in 2001 and is 236 metres in length. Svensson [42] clearly outlines the state of development of cable stayed bridges, but opines that arch bridges are uneconomic if over 300 metres in length. As the current limit is 550 metres, the question is then clearly asked:

Can we build an arch bridge to 1000 metre, the currently posited limit for cable stayed bridges?

The research interest in this work is the application of concentric and eccentric loading to high strength concrete filled steel tubes, this has not been fully investigated previously. The clear application is in the use of CFST for the arch elements for a 1000 metre bridge, which is clearly controlled by compression and eccentric loading. In such a bridge, the use may include a double skin of steel with a concrete infill.

\section{$3 \quad$ Experimental Methods}

\subsection{Test Materials and Methods}

This section of the paper outlines the experimental method.

The CFST experiments were completed using four concrete mix designs and one grade of steel tube. Table 1 lists details of the dry materials used in the four mixes, the properties of the concrete made from the four mixes, and the strength of the concrete determined using $100 \mathrm{~mm}$ sample test cubes. Ordinary Chinese Portland cement corresponding to ACI type I [39] cement was used as binder, natural sand with a fineness modulus of 2.7 was used as fine aggregate, and crushed limestone with a maximum nominal size of $20 \mathrm{~mm}$ was used as coarse aggregate. A mix of finely ground blast furnace slag and fly ash was used in two concrete mixes. A naphthalene super-plasticizer was used to obtain a workable concrete, in accordance with general practice [43].

The concrete was mixed by a forced mixer. The concrete after mixing was cast in the steel tubes, and vibrated to provide the completed specimens. The concentrically loaded CFST specimens and a number of plain concrete test cylinders have the same slenderness ratio of 3.5. The short test specimens were created with a steel base-plate and the top was screeded level to form the final bearing surface for the experiments. The slender tubes were placed upright on a vibrating table and the concrete was cast in layers. The tops of tubes for all column specimens were capped with the same type of steel plate used for the base plate. The slender and eccentrically loaded column tubes were welded to a circular $120 \mathrm{~mm}$ steel base plate, with a thickness of $30 \mathrm{~mm}$. The plate had a 10-mm hole drilled in the center to a depth of $15 \mathrm{~mm}$, which was used to fix the bearing plate.

The concentrically loaded short CFST test samples were labelled A to H. The concentrically loaded slender CFST test samples were labelled S1 to S4. The eccentrically loaded CFST test samples were labelled E0, E1, E2, E3 and ES.

The tests were completed in a new test rig developed for this research work. Thirty-nine columns were subjected to a compression loading. The first test set included nineteen short and nine slender columns tested using a concentric load test-rig. The second test set included eleven slender columns tested using an eccentric load test-rig. The columns had a length to diameter ratio ranging from 3.5 to 15 , which is within the normal range expected in real construction of buildings or in bridges. The characteristic strength of concrete used for the experimental work ranged from $54 \mathrm{MPa}$ to $116 \mathrm{MPa}$. This range of concrete strengths is achievable in modern construction. Figure 2 shows the experimental slender columns after completion of the test work.

Table 2 lists the physical dimensions and the yield strength of the steel tubes, determined from tension tests, for all experiments. Figure 3 shows results of a compressive test series used to determine the stress to strain curves for the three steel cylinder sizes. The tubes were empty for these tests. A number of standard tension tests were completed to determine the elastic properties of the steel.

The confinement index is the theoretical steel tube force capacity divided by the concrete core force capacity, representing the relative contributions of the two elements. Table 3 lists the confinement index for all of the specimens. The concentrically loaded short columns had a confinement index of 0.09 to 0.88 , the concentrically loaded slender column had a confinement index of 0.88 and the eccentrically 
loaded columns had a confinement index of 0.66 to 0.88 . The experimental confinement index is within the normal range used in construction.

The ACI Manual [39] provides limits on the ratio of $D / t$ for composite sections, where $D$ is the diameter and $t$ is the wall thickness. Specimen A has a $D / t$ ratio of 125 , which is greater than the ACI [39] code requirement of 83 for the steel yield stress.

Table 4 lists the geometric and strength properties for each of the eccentrically loaded specimens. This data include the eccentricity of the loading point, $e$, and the ratio of the eccentricity to the radius of the concrete core, $R_{c}$. The specimens, after casting, were cured in an air-conditioned room at a temperature of $20 \pm 2{ }^{\circ} \mathrm{C}$ for 60 days.

A number of plain concrete cylinder test specimens and $100 \mathrm{~mm}$ cube specimens were cast from mix No. 1, mix No. 3 and mix No. 4 at the time of manufacture of the CFST specimens. The plain concrete cylinders were used to investigate the relationship between brittleness, lateral expansion, and strength of the plain concrete. The diameter of the plain concrete test cylinders was $123 \mathrm{~mm}$ and the length was 430 $\mathrm{mm}$. The plain concrete cylinders were sealed and stored with the CFST specimens to match curing conditions used for the concrete filled steel tubes. Plain concrete cylinder tests were not completed on mix No. 2. The plain concrete test cylinders were tested in a 5 mega-Newton capacity testing machine. The plain cylinder samples (length to diameter of 3.5) achieved an average peak stress $f_{c}^{\prime}$ that was $73 \%$ of the mean peak stress for the 100-mm cube specimen, $f_{c u}^{\prime}$. This was the normally expected specimen size effect. This ratio has been used in the analysis of the data.

\subsection{Test Equipment Setup}

Figure 4 shows an annotated test set-up for the short columns tested in concentric loading. A load cell measured the compressive force exerted on the specimens. Four vertical Electrical Resistance Strain (ERS) gauges and four lateral ERS gauges were attached at the mid-height point of steel tubes on the specimens to measure the vertical strain and circumferential strains. Two displacement transducers measured the axial shorting of the concrete and steel tube specimens, whilst the axial shortening of plain concrete cylinders was measured by ERS gages. Data were recorded on a 7V-13 data loggers at a frequency of $4 \mathrm{~Hz}$. Approximately 15 increments of load were applied to each specimen.

Figure 5 shows an annotated schematic arrangement for the slender and eccentric test setup. The experimental test set-up is shown in photographic form in Figure 6 for the slender and eccentric samples. The slender columns were loaded either concentrically or eccentrically to failure. The eccentricity of the applied compressive load was equal at both ends for the eccentrically loaded columns and all were subjected to single curvature bending. Specimens were loaded through knife bearing at the bottom end and hardened steel roller with a 50-mm radius at the top end. For the slender and the eccentrically loaded specimens, the longitudinal strains at the mid-height of specimen were measured by ERS gages. The ERS gages were attached to the exterior of the steel tube in a polar array of 4 gauges at an angular separation of 90 degrees between each of the successive gages. Displacement transducers were used to measure the lateral deflection of the columns at mid-height. Two displacement transducers measured the longitudinal total displacement between the ends of specimen. Approximately 15 increments of load were applied to each specimen. A failure test lasted typically about 40 to 45 minutes. Data recording and loading was identical to the concentric specimens.

\section{$4 \quad$ Results}

This section of the paper outlines the results for the concentric and eccentric tests. An early comment on the paper suggested that additional existing results could be used to improve the quality of the statistical analysis completed for this research work. The section on analysis of the results includes the experimental data from this work and other earlier data [21, 26, 30, 44]

The results for the peak loads, $N_{\mathrm{u}}$, determined for each concentric test specimen are presented in

Table 5. The applied load to the strain in the CFST concentrically loaded specimens is shown in Figure 7. The results for all specimens exhibited initial elastic behaviour, with a brittle failure mode for A and $\mathrm{B}$, and discontinuous yielding for $\mathrm{C}, \mathrm{D}, \mathrm{G}$ and $\mathrm{H}$, and a ductile failure for $\mathrm{E}$ and F. Similar load to 
strain results and failure patterns are observed in other recent experimental results. The unacceptable failure pattern represents a thin walled steel tube exhibiting an elastic strength ridge that was followed by a rapid unloading and significant lowering of the capacity of the CFST, with strain softening. This type of failure is often observed in steel failure in experimental work, refer of course to the classic definitions of steel failure phenomena provided by Baker [45].

The concrete and steel composite unit still exhibits greater strength than an equivalent plain concrete specimen does for equal strain levels. Nevertheless, this type of failure mode is not considered suitable for building construction.

This type of unacceptable brittle or discontinuous failure occurred where the confinement ratio, $\Phi$, is defined by the inequality:

$$
\Phi<0.5
$$

Defining $K$ as the ratio of the steel tensile yield stress $f_{s t}^{\prime}$ to the concrete cylindrical stress $f_{c}^{\prime}$ redefines the confinement ratio as:

$$
\Phi=K\left(\mathrm{~A}_{S} / \mathrm{A}_{c}\right)
$$

Susantha, Ge and Usami $[46,47]$ determined a theoretical uni-axial stress strain curve for confined concrete steel tubular columns, and reported no previous results for the first failure pattern, having only one reported result with a confinement ratio less than 0.5 . The probable lower limit for the confinement index will be likely determined to be somewhere in the range of 0.25 to 0.5 , although a value of 0.5 is currently recommended to ensure acceptable failure modes during extreme loading situations. The confinement ratio can be determined from the inequality established from simple algebraic rearrangement of equations (3) and (4) as shown in equation (5):

$$
8 k t>D_{c}
$$

Here $D_{c}$ is the core diameter. As an example, a typical value $K$ of 5 and a tube with an internal diameter of $400 \mathrm{~mm}$ yields a minimum wall thickness of $10 \mathrm{~mm}$.

The mean value for the ratio of the increase in the measured capacity compared to the sum of the individual capacities is $1.35 \pm 0.17$. A statistical analysis was completed using the standard method, Students' t test. This test provided a statistical comparison of the ratio of the increase in measured capacities to an assumed mean of 1 . The result shows that an observed difference in the measured capacity results is statistically significant at the traditionally accepted 5 percent confidence level. The reasonable conclusion is the interaction of the steel tube with the confined concrete results in an increased measured capacity of the composite units. This conclusion is consistent with the other results from earlier experimental work presented in this paper. Equation (2) can be re-arranged to provide equation (6) that can be solved for the data sets using linear regression with the simplified variables of equation (7) developed for graphing and presentation purposes.

$$
\begin{gathered}
\frac{N_{c}}{A_{c} f_{c}^{\prime}}=\xi+\zeta \frac{A_{s} f_{s t}^{\prime}}{A_{c} f_{c}^{\prime}} \\
\lambda=\xi+\zeta \Phi
\end{gathered}
$$

Here $\lambda$ defines a dummy variable used for linear regression analysis purposes. Equation (7) provides the basis for a linear regression analysis to determine the constants for Equation (2). Figure 8 shows the results for $\lambda$ plotted against $\Phi$ from the current research data shown in Table 5 . The final fitted equation (8), derived from (2) is:

$$
N_{c}=1.16 A_{c} f_{c}^{\prime}+1.52 A_{s} f_{s t}^{\prime}
$$

The residual data have an acceptable normal probability plot, which means that the assumption of a linear regression analysis is reasonable. The standard error on the two coefficients is \pm 0.04 .

A linear regression analysis of the concentrically loaded column results was completed for four CFST experimental data sets as shown in Table 6. Data are obtained also from a number of existing published sources as listed elsewhere in this paper.

The existing and published data sets used for statistical analysis are:

Test Set 1: is based on the peak results for each current experimental specimen and the second current research data set

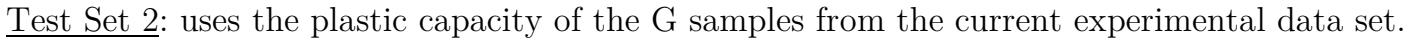


Test Set 3: is the complete result from the published research and the current research results.

Test Set 4: is Test Set 3 without the results for the samples with the butt welded top-plates from Sakino et al. [21].

The $\mathrm{G}$ samples in Test Set 1 are significant outlier points for the linear regression analysis, where the peak elastic load is not established from a simple function as shown in equation (2). The results in Test Set 2 provide a better fit to the data and do not overestimate the plastic capacity of the composite section at higher $\Phi$ indices, when compared to the results for the first test set.

Test Set 3 provides a regression equation for the full set of 89 results, but the results of the normal probability plot for the residual data show a significant deviation from an acceptable result. This result is caused by the inclusion of the samples with the butt welded top plate. These interesting residual data results point to the need for further testing of beam - column connections.

Test Set 4 results for the 53 samples have an acceptable normal probability plot, with the results limited to the test limit of a confinement index of 1.5 .

The Chinese [25] and ACI Concrete [39] codes use a coefficient $\xi$ equal to one. The results from all experiments suggest that a value of 1.1 is reasonable. The Chinese Code and the ACI Concrete Codes use a value of 2 and 1 respectively for the steel coefficient, $\zeta$. The results from all experiments suggest that a value of 1.5 is reasonable. The recommended design equation for concentric loaded CFST tubes is:

$$
N_{c}=1.1 A_{c} f_{c}^{\prime}+1.5 A_{s} f_{s t}^{\prime}
$$

The slender specimens show the buckling failure load, $N_{B U}$, and other results listed in Table 7 . In the table, $\Gamma$ is the ratio of the measured buckling load to the load bearing capacity. The buckling failure loads were determined from the force displacement curves.

The peak results for tests are shown in Figure 9. Figure 9 shows one or two typical curves from each of the slenderness ratio groups. The displacement ratio (\%) represents the ratio of longitudinal deflection of the column in compression to initial length of specimens. It is evident that the peak load bearing capacities and peak displacement ratio for each slender column decrease as the $\frac{L}{D}$ increases. Here $L$ is the column length. The curves have been offset a unit amount to demonstrate the change in the force to strain curve as the slenderness of the columns increases from S1-1 to S4-2.

The current experimental data are plotted in Figure 10 for the ratio of the capacity of the slender column to the capacity of a short column of equal dimensions. As an example from the published results, the results of O'Shea and Bridge $[26,30]$ have a $\frac{L}{D}$ ratio of approximately 3.4 to 3.5 . The proposed equation for the strength reduction factor, $\varphi_{1}$, to account for slenderness for the data shown in Figure 10 is

$$
\varphi_{1}=1-\left[\frac{1}{9}\left(\frac{L}{D}-3.5\right)^{0.5}\right]
$$

The constants in the equation were determined using linear regression. It is considered that equation (11) can be used to calculate the load bearing capacities of slender columns, $N_{C U}$, filled with HSC:

$$
N_{C U}=\varphi_{1} N_{U}
$$

The measured data of ERS strain gages located at mid-height of each column show that at a slenderness ratio of seven and at peak load, the longitudinal strains of steel at interior, right and left sides of curvature plane are $16956 \mu \varepsilon, 9316 \mu \varepsilon$ and $3272 \mu \varepsilon$ respectively. All these values exceed the yield strain. At a slenderness ratio of eleven, the strains at interior and left side are $12578 \mu \varepsilon$ and 11021 $\mu \varepsilon$ respectively, whilst for slenderness ratio of fifteen, the strain at the interior is $3786 \mu \varepsilon$, just exceeding the yield strain. It can be concluded that the slenderness ratio fifteen is a critical value, and after exceeding this slenderness value, the failure mode of the columns changes from one of inelastic instability to an elastic instability.

The eccentrically loaded columns results are shown in Table 8 for the measured failure load. Figure 11 shows a typical curve from each of the eccentricity ratio test groups. The specimens with the same slenderness ratio show the deflection increasing as $e / R_{c}$ increases. However, the relative load corresponding to a rapid increase in the deflection decreases as $e / R_{c}$ increases. A linear regression 
analysis showed that the residual data for the analysis of the measured capacity with respect to $e / R_{c}$ were not randomly distributed. This result points to a data set following a curve rather than a linear function. The capacity of the eccentrically loaded slender columns, $N_{B U}$, is:

$$
N_{B U}=\varphi_{1} \varphi_{2} N_{U}
$$

The Chinese [25] standard provided a general equation (13) to relate the capacity reduction factor $\varphi_{2}$ to the eccentricity ratio $e / R_{c}$. The Chinese standard has $a_{0}=1.8$ for normal strength concrete:

$$
\varphi_{2}=\frac{1}{1+\left(\frac{\mathrm{a}_{0} \mathrm{e}}{R_{c}}\right)}
$$

The experimental data for the eccentric loading from this current research is plotted on Figure 12. The data is shown as the ratio of the measured load to the calculated load of the column. Equation (10) is plotted on Figure 12 for values of $a_{0}=1.8,2.0,2.2$. The residual data for the experimental points measured against a varying $a_{0}$ have been calculated for the equation (13). The results show a reasonably normal distribution for the value of 2.0 for $a_{0}$.

An attempt was made to estimate the Poisson's ratio for the composite material. Figure 13 shows a plot of the longitudinal to transverse strains for samples of 54 and $116 \mathrm{MPa}$ concrete respectively. The results show that in the elastic range a Poisson's ratio of 0.2 would be suitable for design purposes.

\section{$5 \quad$ Analysis of the Results}

This section of the paper outlines the analysis of the results for the concentric and eccentric tests. This work involved the testing of thirty-nine specimens. This analysis section presents the statistical analysis of the current data, these additional published results and provides a comparison with the Chinese and ACI codes of practice.

The first stage is a review of the general linear equation used to estimate the capacity of the CSFT in terms of the goodness of fit to the data sets. All analysis is completed using the general form of equation (2), as the results do not support the simpler assumption implicit in the existing Chinese code formula or the ACI formula. The use of equation (2) instead of Sakino's [21] equation (15) or the Chinese Manual [25] equation (2) provides a direct method to determine the level of conservatism built into the current ACI manual [39] and other similar codes [40].

The results for the CFST short column specimens tested in this research work provide data to extend the fundamental understanding of the properties of short columns subjected to axial compression. This analysis of short column capacity results includes additional experimental data with alternative end loading conditions. The data are available from other published papers. Three of the four alternatives available for the specimen top end restraints have test results available [21, 26, 28-30, 44]. These options are (a) steel plate loaded, (b) concrete surface loaded, (c) concrete and steel tube loaded, and (d) steel tube only loaded. No results are available for steel tube only loading, and it is an unlikely loading condition. The alternative (a) which has a steel top plate has results that do not match the regression model implicit in equation (2). The steel plate results have a residual data set for the regression analysis that does not have an acceptable normal probability plot. This result indicates a probable alternative failure mechanism affects the results for this type of end restraint. It is beyond the scope of our experimental work to resolve this experimental issue; however, the results with the concrete and the steel tube loaded represent the closest experimental method to real field conditions. The ductility of the concrete filled steel tube that is filled with high strength concrete provides an acceptable engineering material provided that the ratio $\frac{D}{t}$ is maintained within the acceptable band presented as an inequality in equation (5). This result is consistent with the published results. Further work is required to determine how close the current limit of 0.5 can be lowered towards the current tested limit of 0.25 . 
Equations (10) and (11) have been shown to provide a reasonable fit to the data for the concentrically loaded slender columns. These equations provide direct calculation of the capacity reduction factor $\varphi_{1}$ given a slenderness ratio for a column.

Equations (12) and (13) have been shown to provide a reasonable fit to the data for the eccentrically loaded slender columns. These equations provide direct calculation of the capacity reduction factor $\varphi_{2}$ given an eccentricity ratio for a column.

As a direct result of early comments on the original paper, a significant amount of additional research is included in the statistical analysis from other experimental work. As with all experimental work challenges exist in comparing different results from different labs. Comments on the comparison problems are firstly $\frac{f_{s t}^{\prime}}{f_{c}^{\prime}}$ is dependent on the type of tests used to determine the yield stress and the size of cylinders used in the concrete testing, which varies between countries [25, 39, 40]. The equation from the Chinese standard [25] for the estimated capacity of a normal strength concrete core in a steel cylinder can be written as follows:

$$
\begin{aligned}
& N_{c}=\eta A_{c} f_{c}^{\prime} \\
& \eta=1+2 \Phi
\end{aligned}
$$

The assumption in the CECS [25] is that the variable $\xi$ from Equation (2) has a value of one. The experimental data, up to this research, tolerably support the form of the Chinese equation, which is:

$$
\eta=1+\xi \Phi
$$

Sakino [21] uses the following equations, (17) and (18), to estimate $f_{c}^{\prime}$ from the characteristic compression strength $f_{c c}$ with $a=1.67$ and $b=-0.112$ for a $100 \mathrm{~mm}$ cylinder standard test.

$$
\begin{aligned}
& \gamma_{u}=a D_{c}^{b} \\
& f_{c}^{\prime}=\gamma_{u} f_{c c}
\end{aligned}
$$

This method of Sakino [21] provides a variant definition of the confinement index as:

$$
\Phi=\frac{A_{s} f_{s t}^{\prime}}{\gamma_{u} f_{c c} A_{c}}
$$

Here $\gamma_{u}$ is a dummy variable. A more standard testing for by Sakino for $f_{c}^{\prime}$ would simplify a comparison of the results and conform with the general recommendations on structural reliability analysis [48].

A second issue is that the experimental condition not examined in previously completed research work is the effect of the upper cap conditions of the test specimens on the experimental results. The alternative treatments for the top of specimens are (a) steel plate loaded, (b) concrete surface loaded, (c) concrete and steel tube loaded, and (d) steel tube only loaded.

Sakino tests [21] of thirty CFST cylinders provide results for one alternative cap finish condition, butt welded steel plate. Figure 14 shows the results of the experimental load $N_{e}$ plotted against the theoretical axial capacity of CFST components $N_{o}$ for the Sakino tests. Sakino concludes that an increase in the capacity of the section is linearly proportional to the steel tube yield load. A plot of the yield strength of the cylinders against the difference of the experimental load and the load combination $N_{t}$ does give a high correlation co-efficient, 0.996, for these Sakino results as shown in Figure 15. Sakino's conclusion from these results is a simple restatement of equation (14) as:

$$
N_{e}-N_{o}=\lambda_{d} N_{s o}
$$

$N_{s o}$ is the calculated load capacity of the CFST. $\lambda_{d}$ is a normalization variable used by Sakino. Sakino normalizes the results with the factor $N_{o}$ with the result that the accuracy of the equation estimating $\lambda_{d}$ reduces to a correlation co-efficient of 0.5 . The $\lambda_{d}$ factor is $0.27 \pm 0.02$ excluding Sakino's $84 \mathrm{MPa}$ samples, and $0.236 \pm 0.015$ for the full set of Sakino results. Sakino's result for $\eta$, correlation co-efficient of 0.99 , from an analysis of this work is: 


$$
\eta=1+1.24 \Phi
$$

O'Shea and Bridge $[26,30]$ completed a set of experiments on CFST samples with concrete strengths ranging from 41 to $108 \mathrm{MPa}$. These researchers used a method of loading the concrete and steel tube, which is alternative (c). O'Shea and Bridge results had a correlation co-efficient of 0.89 [26, 30]. The results from these experiments are

$$
\eta=1+1.41 \Phi
$$

Sufficient data now exist to test the hypothesis $\xi=1$ using the Sakino [21] and the O'Shea and Bridge [26, 30] experimental data sets. The CFST results for the data of Sakino [21] and O'Shea and Bridge $[26,30]$ has been analyzed with linear regression using equation (6). The results are presented in Table 9 including the Z-statistic for the null hypothesis that the various experimental results are taken from the same sample set. These $\mathrm{Z}$ statistic results are statistically significant at the five percent confidence level indicating a systematic difference in the scalar variables in the equation that fits the data in Table 9. The results from this analysis point to a systematic error with the code assumption of a constant $\xi=1$. The reasonable conclusion is that the steel and concrete interact providing an increased composite strength, with variable $\xi$ being greater than unity.

\section{Conclusions}

High Strength Concrete Filled Steel tubes (CFST) provide a common construction material for buildings and bridges in China and elsewhere in the world. There are a number of obvious advantages in using an external steel skin for the concrete, particularly in an area with seismic loads. The purpose of this experimental work was to investigate the improvement in the ductility and compressive strength of the concrete core with the use of confining steel. The differential stiffness between the steel tube and the concrete will result in a compression load on a column in the formation of a bi-axial stress state in the concrete that will increase the apparent strength of the unit. This is analogous to the improvement in strength of masonry when compared with the separate bricks and mortar.

The principal conclusion reached in this experimental research is that the ductility and strength of a high strength concrete column can be significantly improved with a confining steel tube.

A series of experiments were completed on concentric and eccentric circular specimens in two test rigs. The results were compared with experimental work completed by others in the last three decades. The most general linear form of the capacity equation for the combined unit has been used in the statistical analysis. A variation on the form has been developed to determine the constants for the capacity equation using standard linear regression techniques.

The simple regression model developed for the Chinese standard to estimate the capacity of a concrete filled steel tube has been generalized from this experimental analysis. A detailed regression analysis of these results and other recently published concrete filled steel tube experimental data provide a steel coefficient within a range of 1.5 to 1.6 , which is less than the current Chinese code value of 2 for normal strength concrete, and a concrete coefficient within the range of 1.06 to 1.16 . Values of 1.5 and 1.1 are recommended for the steel and concrete coefficient for design purposes. The conclusions for the concentrically loaded slender columns were that the bearing capacity decreases as the slenderness ratio increases and equations (10) and (11) can be used to calculate the bearing capacity of slender concentrically loaded CFST columns. The principal conclusions for eccentrically loaded CFST columns were that the bearing capacity decreases as the eccentricity ratio increases and slenderness ratio increases, and that the design can be based on equations (10), (12), and (13). The results show that the load bearing capacities and peak displacement ratio decrease as the slenderness ratio of the columns increases.

A design engineer in looking to a long span arch bridge, say to 1000 metres, should consider high strength concrete placed inside steel tubes. The steel tubing can be protected against corrosion, and provides a simple method of assembly and the confining effect will significantly increase the apparent strength of the concrete. A preferred design may include an internal walkway provided as a circular element. 
Acknowledgments. The National Science Foundation Committee of China (NSFC) financed the work described in this paper. The authors are grateful for the support from the NSFC.

\section{References}

1. J. Chung, C. Matsui, and K. Tsuda, Simplified design formula of slender concrete filled steel tubular beamcolumns. Structural Engineering \& Mechanics, 2001. 12(1): p. 71-84.

2. M. Elchalakani, X.L. Zhao, and R.H. Grzebieta, Concrete-filled circular steel tubes subjected to pure bending. Journal of Constructional Steel Research, 2001. 57(11): p. 1141-1168.

3. A.A. Golafshani, S.B.B. Aval, and M.A. Saadeghvaziri, The fiber element technique for analysis of concrete-filled steel tubes under cyclic loads. Structural Engineering and Mechanics, 2002. 14(2): p. 119-133.

4. J.F. Hajjar, Composite steel and concrete structural systems for seismic engineering. Journal of Constructional Steel Research, 2002. 58(5-8): p. 703-723.

5. J.F. Hajjar and B.C. Gourley, Representation of concrete-filled steel tube cross-section strength. Journal of Structural Engineering ASCE, 1996. 122(11): p. 1327-1336.

6. J.F. Hajjar and B.C. Gourley, A cyclic nonlinear model for concrete-filled tubes .1. formulation. Journal of Structural Engineering ASCE, 1997. 123(6): p. 736-744.

7. J.F. Hajjar, B.C. Gourley, and M.C. Olson, A cyclic nonlinear model for concrete-filled tubes .2. verification. Journal of Structural Engineering ASCE, 1997. 123(6): p. 745-754.

8. J.F. Hajjar, et al. Seismic Analysis of Concrete-Filled Steel Tube Beam-Columns and Three-Dimensional Composite Frames. in Composite Construction in Steel and Concrete III,. 1996. New York: Engineering Foundation, American Society of Civil Engineers.

9. J.F. Hajjar, A. Molodan, and P.H. Schiller, A distributed plasticity model for cyclic analysis of concrete-filled steel tube beam-columns and composite frames. Engineering Structures, 1998. 20(4-6): p. 398-412.

10.J.F. Hajjar, P.H. Schiller, and A. Molodan, A distributed plasticity model for concrete-filled steel tube beamcolumns with interlayer slip. Engineering Structures, 1998. 20(8): p. 663-676.

11.H.-L. Hsu and H.-L. Yu, Seismic performance of concrete-filled tubes with restrained plastic hinge zones. Journal of Constructional Steel Research, 2003. 59(5): p. 587-608.

12.K. Nakanishi, T. Kitada, and H. Nakai, Experimental study on ultimate strength and ductility of concrete filled steel columns under strong earthquake. Journal of Constructional Steel Research, 1999. 51(3): p. 297-319.

13.L. Jidu, Study on the load bearing capacity of concrete filled steel tubular columns. Industrial Building, 1985(2): p. $25-31$.

14.B. Kato, Column Curves of Steel-Concrete Composite Members. Journal of Constructional Steel Research, 1996. 39(2): p. 121-135.

15.R.W. Furlong, Strength of steel encased concrete beam-columns. Journal of Structural Engineering ASCE, 1967. 93(ST5): p. 113-124.

16.H. Weichun and X. Changchun, The application of steel tubular concrete in the manufacture and business building of Jiangsu Post and Communication Administration Bureau. Journal of Nanjing Architectural and Civil Engineering Institute, 1999(1): p. 68-72.

17.J. Webb and J.J. Peyton. Composite Concrete Filled Steel Tube Columns. in Structural Engineering Conference. 1990. Adelaide, SA: The Institution of Engineers, Australia.

18.C.W. Roeder, Overview of hybrid and composite systems for seismic design in the United States. Eng Struct, 1998. 20(4-6): p. 355-363.

19.C.W. Roeder. CFT Research in the US Japan Program. in ASCE Structures Congress. 1997. Portland Oregon: ASCE.

20.C. Lizhu, Introduction of the utilization of CFT in Shenzhen Saige building. Journal of Harbin Jianzhu University, 1997(5): p. 14-16.

21.K. Sakino, et al., Behavior of Centrally Loaded Concrete Filled Steel Tube Short Columns. Journal of Structural Engineering, 2004. 130(2): p. 180-8.

22.Y. Sakumoto, et al., Fire Resistance of Concrete Filled Fire-Resistant Steel-Tube Columns. Journal of Materials in Civil Engineering, 1994. 6(2): p. 169-183. 
23.C. Shaohuai and G. Wanli, Properties and strength calculation of steel tubular concrete slender columns. Journal of Building Structures, 1985. 6(1): p. 32-40.

24.C. Shaohuai and D. Xiaotan, Properties and strength calculation of eccentrically loaded steel tubular concrete columns. Journal of Building Structures, 1984. 6(4): p. 32-41.

25.CECS, Design and construction regulation of CFST structures. 1990, China Engineering Construction Association Standard.

26.M.D. O'Shea and R.Q. Bridge, Design of Circular Thin Walled Concrete Filled Steel Tubes. Journal of Structural Engineering, 2000. 126(11): p. 1295-1303.

27.T. Guanzuo and Z. Bingquan, Load bearing capacity calculation of steel tubular concrete columns. Industrial Building,, 1985(2): p. 21-25.

28.A.E. Kilpatrick, The behaviour of high-strength composite concrete columns, in School of Civil Engineering,. 1996, Curtin University of Technology: Perth. p. 317.

29.A.E. Kilpatrick and B.V. Rangan, Influence of interfacial shear transfer on behavior of concrete-filled steel tubular columns. ACI Structural Journal, 1999. 96(4): p. 642-648.

30.M.D. O'Shea and R.Q. Bridge, Design of Thin-walled Concrete Filled Steel Tubes. 1997, The University of Sydney: Sydney. p. 91.

31.C. Shaohuai and J. Zhanshuan, Properties and strength calculation of concrete filled steel tubular short columns. Journal of Building Structures, 1984(6): p. 13-28.

32.C. Shaohuai, Concrete filled steel tubular structures. 1989: China Construction Publishing House.

33.D. Krajcinovic, Damage Mechanics. 1996, New York: Elsevier.

34.M.-X. Xiong, D.-X. Xiong, and J.Y.R. Liew, Flexural performance of concrete filled tubes with high tensile steel and ultra-high strength concrete. Journal of Constructional Steel Research, 2017. 132: p. 191-202.

35.Y. Chen, et al., Bond-slip behaviour of concrete-filled stainless steel circular hollow section tubes. Journal of Constructional Steel Research, 2017. 130: p. 248-263.

36.Y.M. Alostaz and S.P. Schneider, Analytical Behavior of Connections to Concrete-filled Steel Tubes. Journal of Constructional Steel Research, 1996. 40(2): p. 95-127.

37.M. Mursi and B. Uy, Strength of Concrete Filled Steel Box Columns incorporating Interaction Buckling. Journal of Structural Engineering, 2003. 129(5): p. 626-639.

38.L.-H. Han, Fire performance of concrete filled steel tubular beam-columns. Journal of Constructional Steel Research, 2001. 57(6): p. 697-711.

39.ACI Committee 318, Building Code Requirements for Structural Concrete (ACI 318-99) and Commentary (ACI 318R-99). 1999, American Concrete Institute: Farmington Hills, MI.

40.Standards Australia, AS 3600 Concrete Structures. 2009, Standards Australia,: Sydney.

41.Wikipedia contributors. Beipan River Shuibai Railway Bridge. 2017 (2017, January 18); Available from: https://en.wikipedia.org/w/index.php?title=Beipan_River_Shuibai_Railway_Bridge\&oldid=760627937.

42.H. Svensson, Cable Stayed Bridges 40 years of Experience Worldwide. 2012, Weinheim, Deutschland: Ernst and Sohn.

43.N.L. Holland, A.B. Nichols, and J.M. Nichols, Concrete Manfactured with Coconut Fiber Volume I. 2012, College Station: Texas A\&M University.

44.T. Fujimoto, et al., Behaviour of Eccentrically loaded Concrete-Filled Steel Tubular Columns. Journal of Structural Engineering, 2004. 130(2): p. 203-212.

45.J. Baker, M.R. Horne, and J. Heyman, The Steel Skeleton - Plastic Behaviour and Design. Vol. II. 1965, Cambridge, UK: CUP.

46.K.A.S. Susantha, Ge H. B., and Usami T., Stress strain relationship for confined concrete in circular, box, and octagonal shaped steel columns., in Proc. of the Second International Summer Symposium,. 2000: Tokyo, Japan, p. $49-52$.

47.K.A.S. Susantha, H. Ge, and T. Usami, Uniaxial stress-strain relationship of concrete confined by various shaped steel tubes. Engineering Structures, 2001. 23(10): p. 1331-1347.

48.R.E. Melchers, Structural Reliability Analysis and Prediction. 1999, Chichester: Wiley. 


\section{Appendix: Tables}

Table 1. Mix and concrete properties

\begin{tabular}{l|l|l|l|l|l|l|l|l|l|l}
\hline Mix & \multicolumn{9}{l|}{ Concrete Mix Components $\left(\mathrm{kg} / \mathrm{m}^{3}\right)$} & \multicolumn{1}{l}{ Concrete Properties } \\
\hline$\#$ & Cement & Silica Fume & Slag & Fly Ash & Sand & Gravel & Super plasticiser $\left(\mathrm{kg} / \mathrm{m}^{3}\right)$ & $\frac{w}{s+c}(\%)$ & Slump $(\mathrm{mm})$ & $f_{c u}^{\prime}(\mathrm{MPa})$ \\
\hline 1 & 585 & 65 & 0 & 0 & 684 & 1024 & 12.4 & 21 & 220 & 116 \\
\hline 2 & 520 & 0 & 65 & 65 & 676 & 1004 & 12.4 & 22 & 220 & 106 \\
\hline 3 & 480 & 0 & 60 & 60 & 653 & 980 & 6.0 & 30 & 230 & 83 \\
\hline 4 & 380 & 0 & 0 & 0 & 688 & 1030 & 1.1 & 49 & 180 & 54 \\
\hline
\end{tabular}

Table 2. Test specimen dimensions

\begin{tabular}{l|l|l|l|l|l|l|l}
\hline \multicolumn{2}{l|}{ Samples } & \multicolumn{5}{l}{ Steel Tube Details } \\
\hline Units Tag & Number of Specimens & $D(\mathrm{~mm})$ & $t(\mathrm{~mm})$ & $L(\mathrm{~mm})$ & $f_{s}^{\prime}(\mathrm{MPa})$ & $\frac{D}{t}$ & $\frac{L}{D}$ \\
\hline
\end{tabular}

\begin{tabular}{l|l|l|l|l|l|l|l}
\hline \multicolumn{2}{l}{ Concentrically Loaded Short Columns } \\
\hline $\mathrm{A}$ & 2 & 125 & 1 & 438 & 232 & 125 & 3.5 \\
\hline $\mathrm{B}$ & 2 & 127 & 2 & 445 & 258 & 64 & 3.5 \\
\hline $\mathrm{C}$ & 2 & 133 & 3.5 & 465 & 352 & 38 & 3.5 \\
\hline $\mathrm{D}$ & 2 & 133 & 4.7 & 465 & 352 & 28 & 3.5 \\
\hline $\mathrm{E}$ & 2 & 133 & 4.7 & 465 & 352 & 28 & 3.5 \\
\hline $\mathrm{F}$ & 3 & 133 & 4.7 & 465 & 352 & 28 & 3.5 \\
\hline $\mathrm{G}$ & 3 & 127 & 7 & 445 & 429 & 18 & 3.5 \\
\hline $\mathrm{H}$ & 3 & 108 & 4.5 & 378 & 358 & 24 & 3.5 \\
\hline
\end{tabular}

\begin{tabular}{l|l|l|l|l|l|l|l}
\hline \multicolumn{1}{l}{ Concentrically Loaded Slender Columns } & 108 & 4.5 & 378 & 358 & 30 & 3.5 \\
\hline S1 & 3 & 108 & 4.5 & 756 & 358 & 30 & 7 \\
\hline S2 & 2 & 108 & 4.5 & 1188 & 358 & 30 & 11 \\
\hline S3 & 2 & 108 & 4.5 & 1620 & 358 & 30 & 15 \\
\hline S4 & 2 & \multicolumn{5}{l}{} \\
\hline Eccentrically Loaded Columns \\
\hline E0 & 3 & 133 & 4.7 & 465 & 352 & 28 & 3.5 \\
\hline E1 & 2 & 133 & 4.7 & 465 & 352 & 28 & 3.5 \\
\hline E2 & 2 & 133 & 4.7 & 465 & 352 & 28 & 3.5 \\
\hline E3 & 2 & 133 & 4.7 & 465 & 352 & 28 & 3.5 \\
\hline ES-1 & 1 & 108 & 4.5 & 756 & 358 & 24 & 7 \\
\hline ES-2 & 1 & 108 & 4.5 & 1620 & 358 & 24 & 15 \\
\hline
\end{tabular}

Table 3. Confinement index details

\begin{tabular}{l|l|l|l}
\hline \multirow{2}{*}{ Units Tag } & \multicolumn{2}{|c|}{ Strength of Concrete } & \multirow{2}{*}{} \\
\cline { 2 - 3 } & $f_{c u}^{\prime}(\mathrm{MPa})$ & $f_{c}^{\prime}(\mathrm{MPa})$ & \\
\hline \multicolumn{3}{|c}{ Concentrically Loaded Short Columns } \\
\hline $\mathrm{A}$ & 116 & 84.7 & 0.09 \\
\hline $\mathrm{B}$ & 116 & 84.7 & 0.20 \\
\hline $\mathrm{C}$ & 116 & 84.7 & 0.48 \\
\hline $\mathrm{D}$ & 116 & 84.7 & 0.66 \\
\hline $\mathrm{E}$ & 54 & 39.4 & 1.41 \\
\hline $\mathrm{F}$ & 83 & 61.3 & 0.92 \\
\hline $\mathrm{G}$ & 116 & 84.7 & 1.33 \\
\hline
\end{tabular}




\begin{tabular}{l|l|l|l}
\hline $\mathrm{H}$ & 106 & 77.4 & 0.88 \\
\hline \multicolumn{4}{l|}{ Concentrically Loaded Slender Columns } \\
\hline $\mathrm{S}$ & 106 & 77.4 & 0.88 \\
\hline \multicolumn{5}{l|}{} \\
\hline Eccentrically Loaded Columns \\
\hline $\mathrm{ES}$ & 116 & 84.7 & 0.66 \\
\hline
\end{tabular}

Table 4. Geometric and strength details of eccentrically loaded specimen

\begin{tabular}{l|l|l|l|l|l|l|l|l|l|l}
\hline Number & $D(\mathrm{~mm})$ & $t(\mathrm{~mm})$ & $L(\mathrm{~mm})$ & $\frac{L}{D}$ & $f_{s t}^{\prime}(\mathrm{MPa})$ & $f_{c u}^{\prime}(\mathrm{MPa})$ & $A_{c}(\mathrm{~mm} 2)$ & $\Phi$ & $e(\mathrm{~mm})$ & $\frac{e}{R}$ \\
\hline E0-1 & 133 & 4.7 & 465 & 3.5 & 352 & 116 & 11998 & 0.66 & 0 & 0 \\
\hline E0-2 & 133 & 4.7 & 465 & 3.5 & 352 & 116 & 11998 & 0.66 & 0 & 0 \\
\hline E0-3 & 133 & 4.7 & 465 & 3.5 & 352 & 116 & 11998 & 0.66 & 0 & 0 \\
\hline E1-1 & 133 & 4.7 & 465 & 3.5 & 352 & 116 & 11998 & 0.66 & 13.3 & 0.22 \\
\hline E1-2 & 133 & 4.7 & 465 & 3.5 & 352 & 116 & 11998 & 0.66 & 13.3 & 0.22 \\
\hline E2-1 & 133 & 4.7 & 465 & 3.5 & 352 & 116 & 11998 & 0.66 & 26.6 & 0.43 \\
\hline E2-2 & 133 & 4.7 & 465 & 3.5 & 352 & 116 & 11998 & 0.66 & 26.6 & 0.43 \\
\hline E3-1 & 133 & 4.7 & 465 & 3.5 & 352 & 116 & 11998 & 0.66 & 39.9 & 0.65 \\
\hline E3-2 & 133 & 4.7 & 465 & 3.5 & 352 & 116 & 11998 & 0.66 & 39.9 & 0.65 \\
\hline ES-1 & 108 & 4.5 & 756 & 7 & 358 & 106 & 7,698 & 0.88 & 13.3 & 0.27 \\
\hline ES-2 & 108 & 4.5 & 1620 & 15 & 358 & 106 & 7,698 & 0.88 & 13.3 & 0.27 \\
\hline
\end{tabular}

Table 5. Concentrically loaded column experimental results

\begin{tabular}{|c|c|c|c|c|c|c|c|}
\hline Specimen & $\begin{array}{l}N_{u} \\
(\mathrm{kN})\end{array}$ & $\begin{array}{l}N_{o} \\
(\mathrm{kN})\end{array}$ & $\begin{array}{l}\text { Ratio of the } \\
\text { Capacities } \\
{\left[N_{u} / N_{o}\right]}\end{array}$ & $\begin{array}{l}\text { Failure } \\
\text { Mechanism }\end{array}$ & $\begin{array}{l}\text { Lower Yield } \\
\text { Point } \\
\text { Capacity } \\
(\mathrm{kN})\end{array}$ & $\begin{array}{l}\text { Plastic } \\
\text { Failure } \\
\text { Point } \\
(\mathrm{kN})\end{array}$ & Comments \\
\hline $\mathrm{A} 1$ & 1275 & \multirow{2}{*}{1096} & 1.16 & \multirow{2}{*}{ Elastic Brittle } & \multirow{4}{*}{ NA. } & \multirow{2}{*}{ NA. } & \multirow{2}{*}{$\begin{array}{l}\text { The residue strength at a strain of } 1 \% \text { is } \\
600 \mathrm{kN}\end{array}$} \\
\hline $\mathrm{A} 2$ & 1239 & & 1.13 & & & & \\
\hline B1 & 1491 & \multirow{2}{*}{1290} & 1.23 & \multirow{2}{*}{ Elastic Brittle } & & \multirow{2}{*}{ N.A. } & \multirow{2}{*}{$\begin{array}{l}\text { The residual plastic strength is about } \\
800 \mathrm{kN} \text { at } 3 \% \text { strain. }\end{array}$} \\
\hline $\mathrm{B} 2$ & 1339 & & 1.11 & & & & \\
\hline $\mathrm{C} 1$ & 1995 & \multirow{3}{*}{1557} & 1.28 & \multirow{3}{*}{$\begin{array}{l}\text { Discontinuous } \\
\text { yielding }\end{array}$} & \multirow{3}{*}{1400} & 1700 & \multirow{3}{*}{$\begin{array}{l}\text { A large plastic deformation at a } \\
\text { constant stress at } 1 \% \text { strain }\end{array}$} \\
\hline $\mathrm{C} 2$ & 1991 & & 1.28 & & & 1700 & \\
\hline $\mathrm{C} 3$ & 1962 & & 1.26 & & & 1500 & \\
\hline D1 & 2273 & \multirow{3}{*}{1683} & 1.35 & \multirow{3}{*}{$\begin{array}{l}\text { Discontinuous } \\
\text { yielding }\end{array}$} & 1600 & 2300 & \multirow{3}{*}{$\begin{array}{l}\text { A less pronounced plastic deformation at } \\
\text { the upper yield point. }\end{array}$} \\
\hline D2 & 2158 & & 1.28 & & 1750 & 1800 & \\
\hline D3 & 2253 & & 1.34 & & 2100 & 1700 & \\
\hline $\mathrm{E} 1$ & 1535 & \multirow{2}{*}{1140} & 1.35 & \multirow{2}{*}{ Ductile Failure } & \multirow{4}{*}{ NA. } & 1535 & \multirow{2}{*}{$\begin{array}{l}\text { Typical failure and desirable curve for } \\
\text { material }\end{array}$} \\
\hline $\mathrm{E} 2$ & 1462 & & 1.28 & & & 1462 & \\
\hline $\mathrm{F} 1$ & 1912 & \multirow{2}{*}{1403} & 1.36 & \multirow{2}{*}{ Ductile Failure } & & 1920 & \multirow{2}{*}{$\begin{array}{l}\text { Typical failure and desirable curve for } \\
\text { material }\end{array}$} \\
\hline $\mathrm{F} 2$ & 1981 & & 1.41 & & & 1980 & \\
\hline G1 & 3404 & \multirow{3}{*}{1981} & 1.71 & \multirow{3}{*}{$\begin{array}{l}\text { Discontinuous } \\
\text { yielding }\end{array}$} & 2400 & 2700 & \multirow{3}{*}{$\begin{array}{l}\text { Ductile discontinuous yielding with a } \\
\text { ductile behaviour but energy snapback } \\
\text { at } 2 \% \text { strain and limited plastic strength } \\
\text { is problematic for earthquake design }\end{array}$} \\
\hline G2 & 3370 & & 1.70 & & 2400 & 2700 & \\
\hline G3 & 3364 & & 1.70 & & 2400 & 2700 & \\
\hline $\mathrm{H} 1$ & 1535 & \multirow{3}{*}{1120} & 1.37 & \multirow{3}{*}{$\begin{array}{l}\text { Discontinuous } \\
\text { yielding }\end{array}$} & 1400 & 1400 & \multirow{3}{*}{ Better than Specimen G. } \\
\hline $\mathrm{H} 2$ & 1578 & & 1400 & & 1200 & 1300 & \\
\hline H3 & 1518 & & 1200 & & & & \\
\hline
\end{tabular}


Table 6. Four CFST test results- regression results after sakino and O'Shea [21], [26]

\begin{tabular}{l|l|l|l|c}
\hline Test Set & No. & $\xi($ Concrete) & $\zeta$ (Steel) & $R^{2}$ \\
\hline 1. Current Test Data & 20 & $1.0 \pm 0.12$ & $1.87 \pm 0.14$ & 0.91 \\
\hline 2. Current Test Data and plastic capacity for Sample G & 20 & $1.16 \pm 0.04$ & $1.52 \pm 0.05$ & 0.98 \\
\hline 3 Available data & 89 & $1.17 \pm 0.03$ & $1.19 \pm 0.01$ & 0.98 \\
\hline 4 Available data without butt welded plate results & 53 & $1.06 \pm 0.02$ & $1.61 \pm 0.03$ & 0.98 \\
\hline
\end{tabular}

Table 7. Slender column buckling failure loads and other data

\begin{tabular}{lllllll}
\hline Number & $\Phi$ & $N_{u}(\mathrm{kN})$ & Measured & $N_{B U}(\mathrm{kN})$ & Measured & $\frac{L}{D}$ \\
\hline S1-1 & 0.88 & 1539 & 1535 & 1.00 & 3.5 \\
S1-2 & 0.88 & 1539 & 1578 & 1.03 & 3.5 \\
S1-3 & 0.88 & 1539 & 1518 & 0.99 & 3.5 \\
S2-1 & 0.88 & 1539 & 1286 & 0.84 & 7 \\
S2-2 & 0.88 & 1539 & 1280 & 0.83 & 7 \\
S3-1 & 0.88 & 1539 & 1194 & 0.78 & 11 \\
S3-2 & 0.88 & 1539 & 1232 & 0.80 & 11 \\
S4-1 & 0.88 & 1539 & 974 & 0.63 & 15 \\
S4-2 & 0.88 & 1539 & 1018 & 0.66 & 15 \\
\hline
\end{tabular}

Table 8. Eccentric column buckling failure loads and other data

\begin{tabular}{l|l|l|l|l|l|l|l}
\hline Test & $\frac{L}{D}$ & $\Phi$ & $N_{u}(\mathrm{kN})$ & $\frac{e}{R_{c}}$ & $\Gamma$ & $N_{c u}(\mathrm{kN})$ & Measured Failure Load $(\mathrm{kN})$ \\
\hline E0-1 & 3.5 & 0.66 & 2220 & 0 & 1 & 2220 & 2273 \\
\hline E0-2 & 3.5 & 0.66 & 2220 & 0 & 1 & 2220 & 2158 \\
\hline E0-3 & 3.5 & 0.66 & 2220 & 0 & 1 & 2220 & 2253 \\
\hline E1-1 & 3.5 & 0.66 & 2220 & 0.22 & 1 & 2220 & 1540 \\
\hline E1-2 & 3.5 & 0.66 & 2220 & 0.22 & 1 & 2220 & 1593 \\
\hline E2-1 & 3.5 & 0.66 & 2220 & 0.43 & 1 & 2220 & 1173 \\
\hline E2-2 & 3.5 & 0.66 & 2220 & 0.43 & 1 & 2220 & 1167 \\
\hline E3-1 & 3.5 & 0.66 & 2220 & 0.65 & 1 & 2220 & 1001 \\
\hline E3-2 & 3.5 & 0.66 & 2220 & 0.65 & 1 & 2220 & 990 \\
\hline ES-1 & 7 & 0.88 & 15781 & 0.27 & 0.84 & 1310 & 889 \\
\hline ES-2 & 15 & 0.88 & 1578 & 0.27 & 0.63 & 1009 & 682 \\
\hline
\end{tabular}

Table 9. Analysis of O'Shea and sakino results

\begin{tabular}{l|l|l}
\hline Test Set & $\xi$ (Concrete) & $\zeta$ (Steel) \\
\hline $\begin{array}{l}\text { 1. O'Shea } \\
\text { Loading Steel and Concrete }\end{array}$ & $\begin{array}{l}1.01 \pm 0.03 \\
(15 \text { specimens })\end{array}$ & $1.41 \pm 0.21$ \\
\hline $\begin{array}{l}\text { 2. Sakino } \\
\text { Butt welded } 12 \mathrm{~mm} \text { plate }\end{array}$ & $\begin{array}{l}1.17 \pm 0.03 \\
(36 \text { Results })\end{array}$ & $1.19 \pm 0.013$ \\
\hline 3. O'Shea Loading Concrete & $\begin{array}{l}1.11 \pm 0.025 \\
(18 \text { specimens })\end{array}$ & $1.52 \pm 0.09$ \\
\hline Z Statistic Test Set 1 to 2 & 16 & 6 \\
\hline Z Statistic Test Set 1 to 3 & 12 & 3.2 \\
\hline Z Statistic Test Set 2 to 3 & 7 & 15 \\
\hline
\end{tabular}

${ }^{1}$ The peak failure load was used for this analysis as it provides a better fit to the remaining data. 


\section{Appendix: Figures}

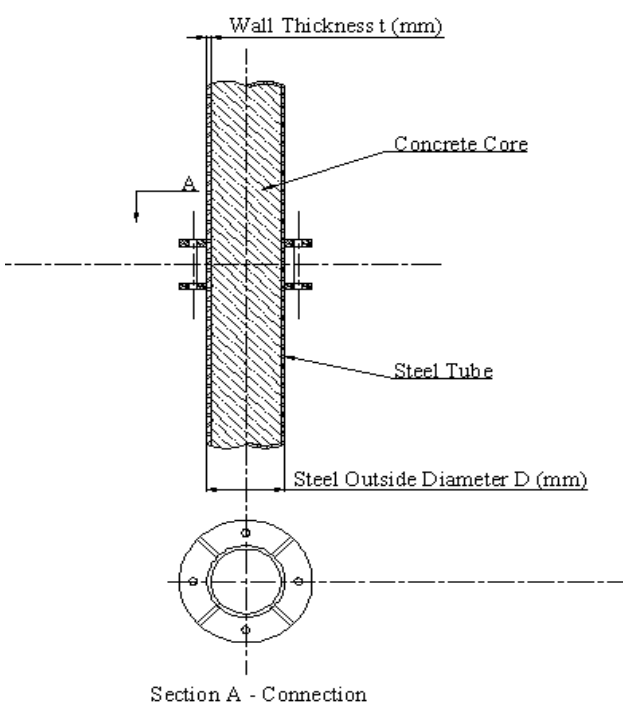

Figure 1. Sample steel connection from a high-rise building in China

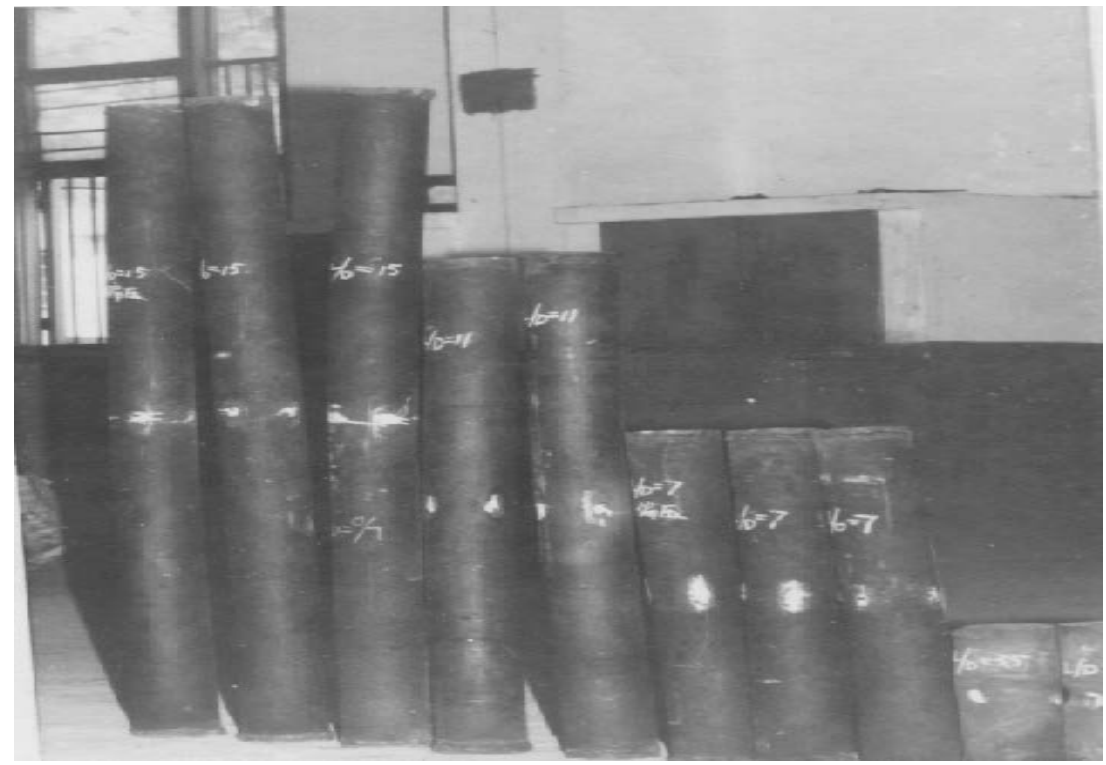

Figure 2. Experimental samples, slender tubes shown after completion of testing 


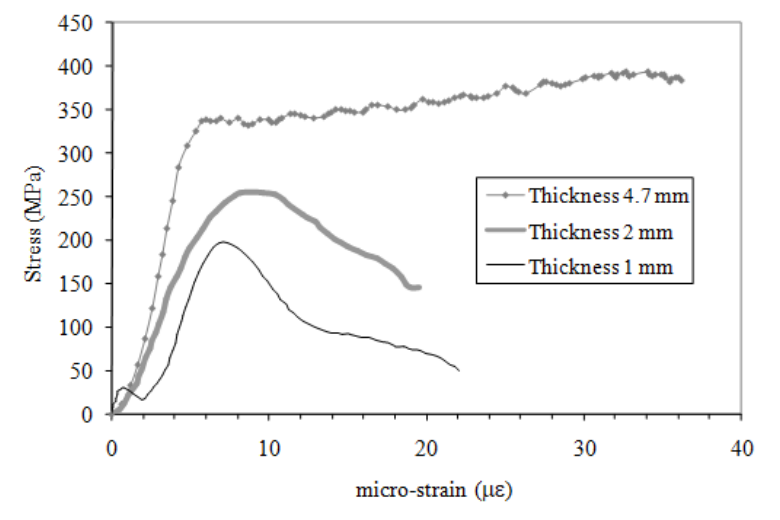

Figure 3. Steel tubes - compression test results.

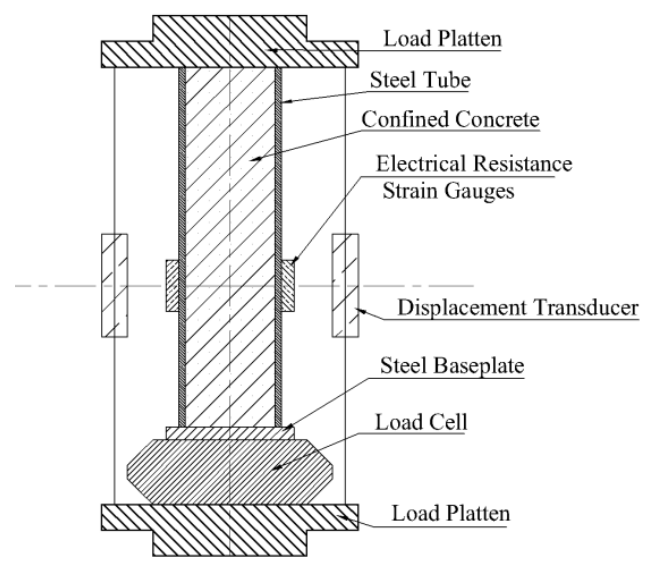

Figure 4. Experimental test set-up for the concentric load tests.

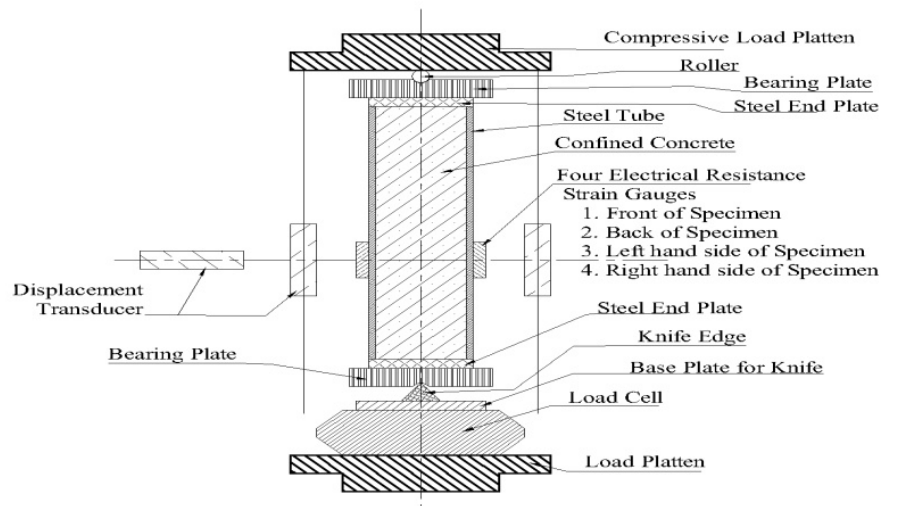

Figure 5. Experimental test set-up for the slender concentric and eccentric load tests 

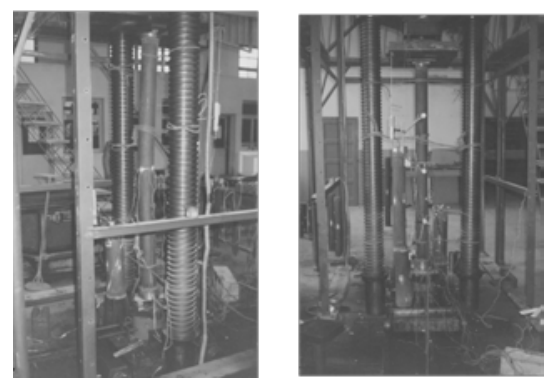

Figure 6. Photographs of the test set up for the slender and eccentrically loaded columns
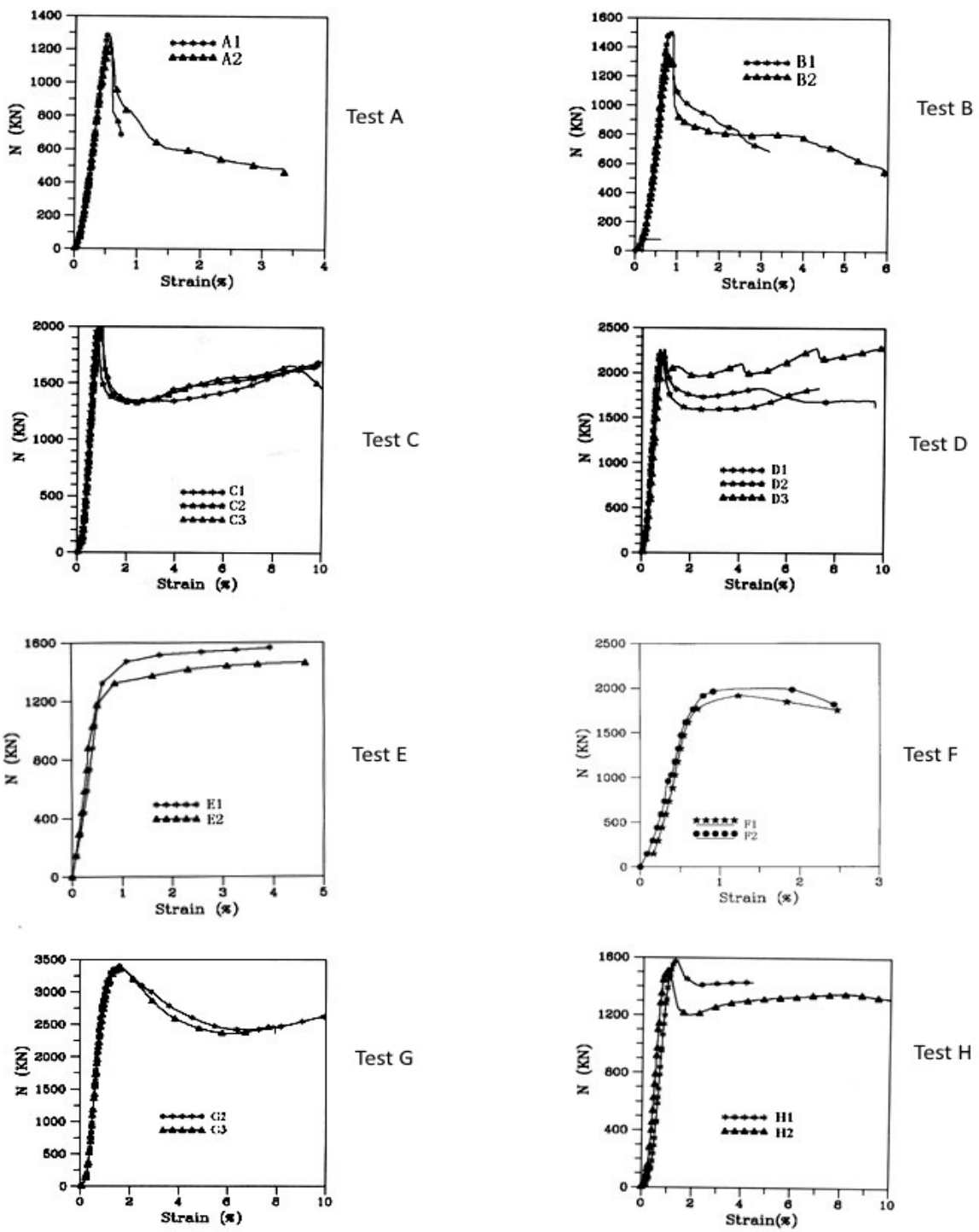

Figure 7. Load to strain curves for the concentrically loaded columns tests A to H 


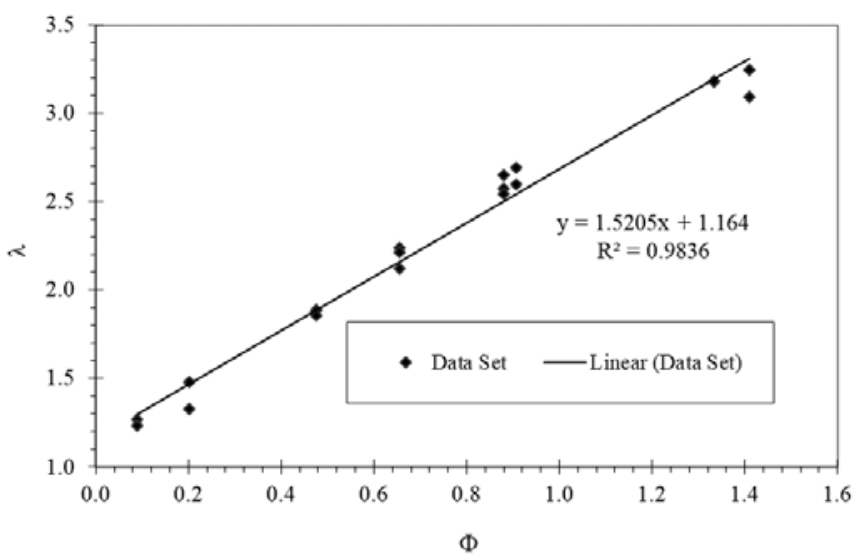

Figure 8. Equation 7 linear regression analysis for variable $\lambda$ plotted against variable $\Phi$

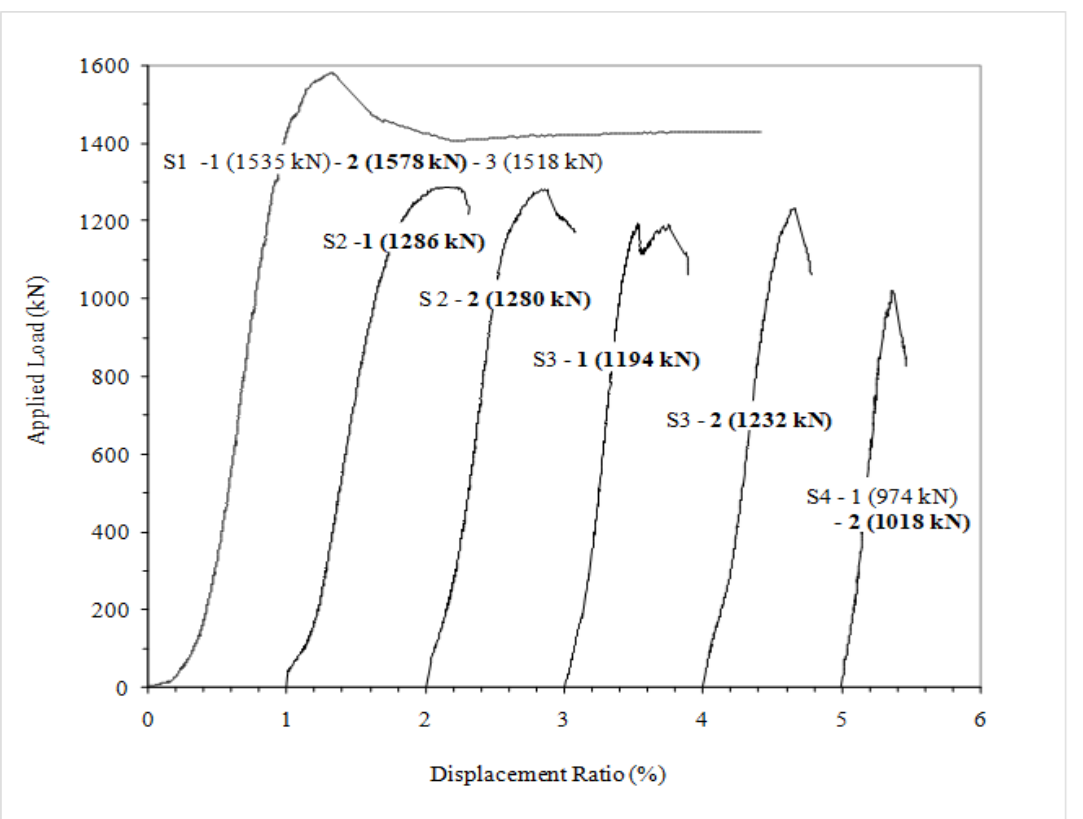

Figure 9. Load to displacement ratio for the slender concentrically loaded columns

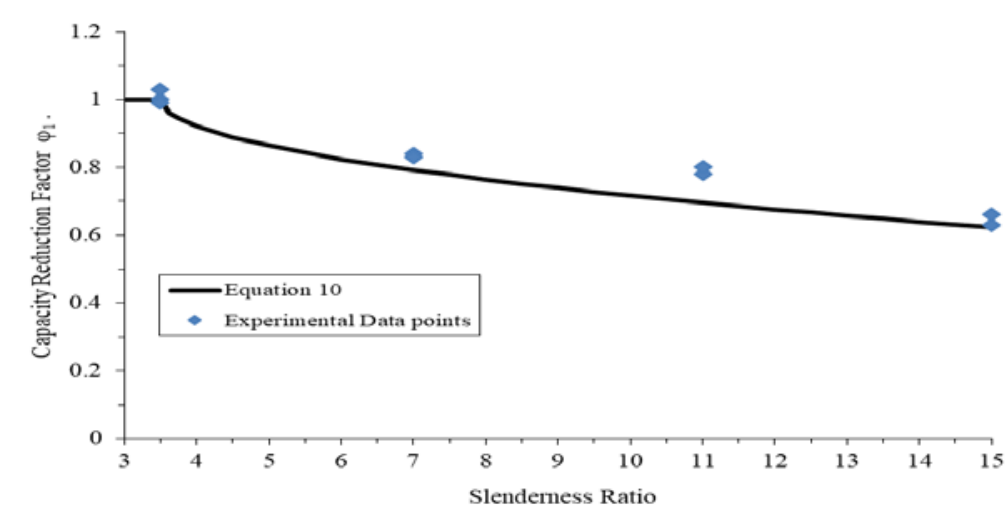

Figure 10. Slender concentrically loaded columns - capacity reduction factor $\phi_{1}$ 


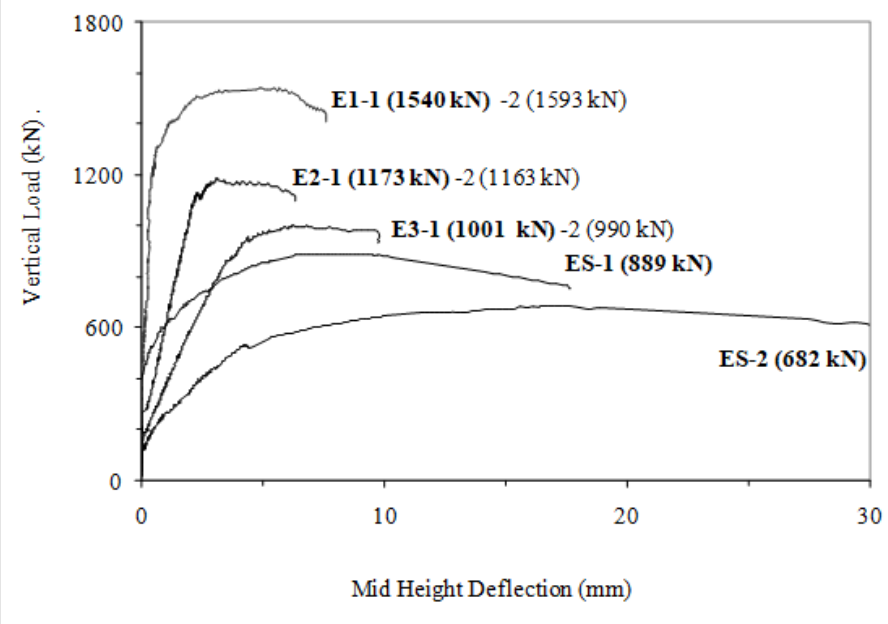

Figure 11. Load to displacement ratio for the eccentrically loaded columns

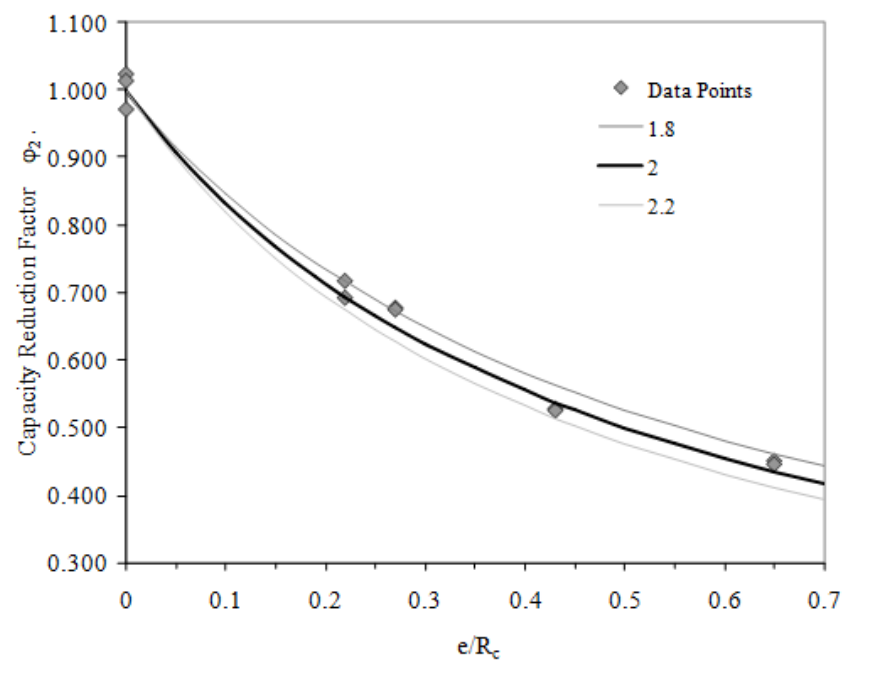

Figure 12. Eccentrically loaded columns - capacity reduction factor $\phi_{2}$ 


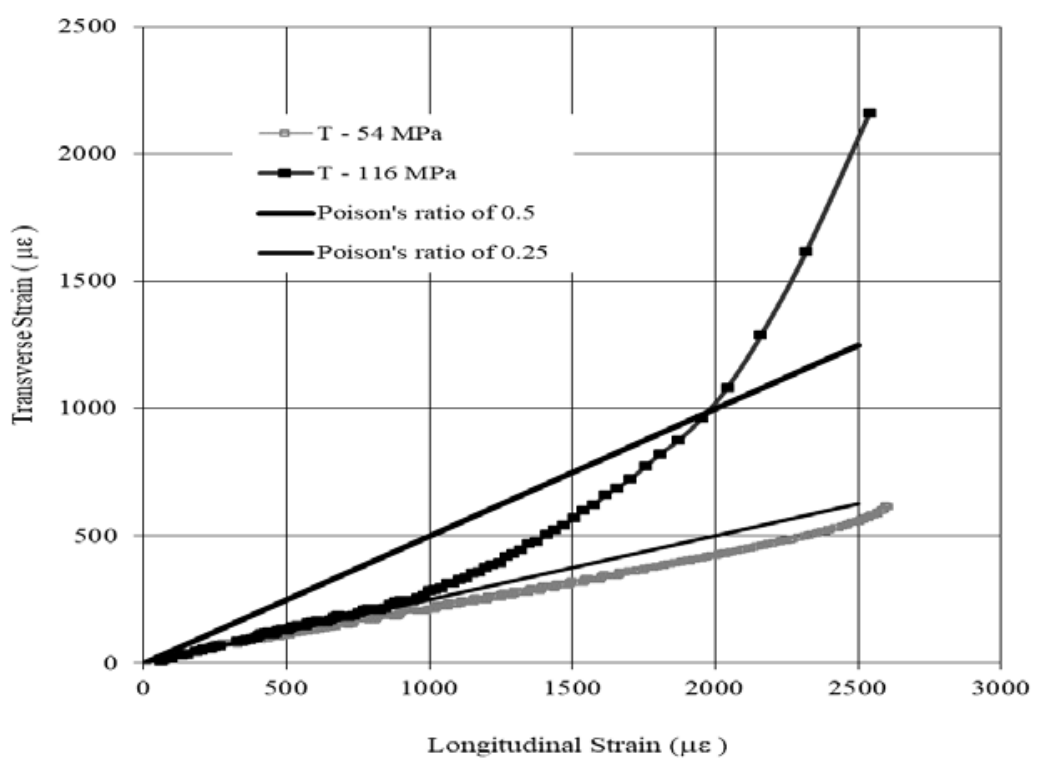

Figure 13. Longitudinal to transverse strains

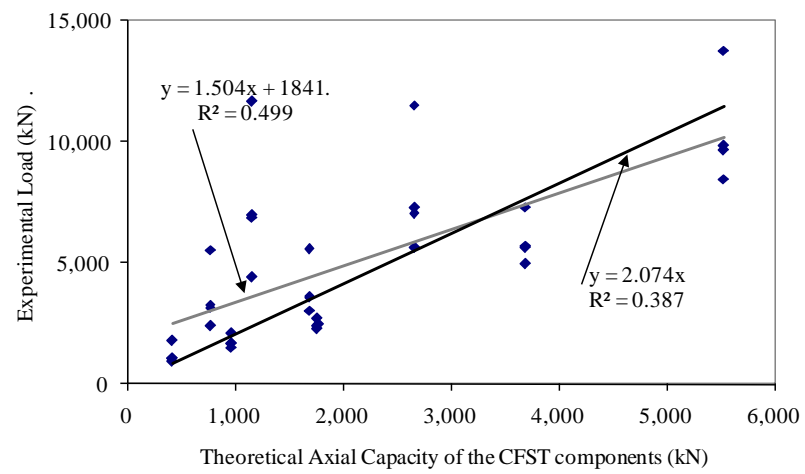

Figure 14. Sakino results for CFST

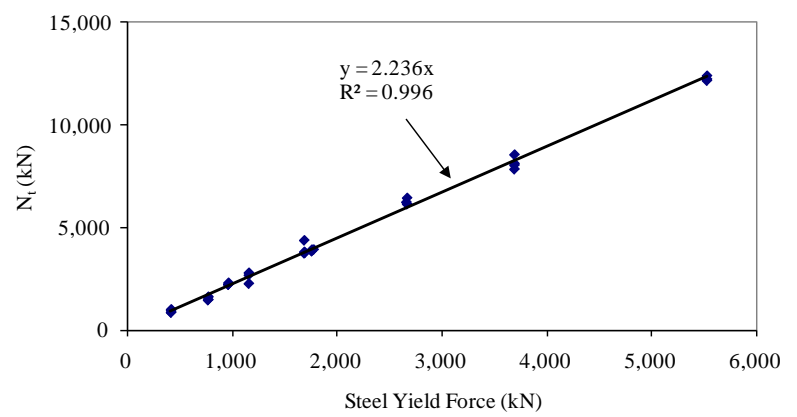

Figure 15. Sakino results for CFST steel tubes 